\section{Comment on journal} review of 'Use of depot medroxyprogesterone acetate contraception and incidence of bone fracture'

We thank Dr Curry for an accurate summary ${ }^{1}$ of our study entitled 'Use of depot medroxyprogesterone acetate contraception and incidence of bone fracture. ${ }^{2}$ Nevertheless, we do not recommend more selective use of depot medroxyprogesterone acetate (DMPA) on account of fracture risk, as we believe that this recommendation would reduce access to an effective, safe contraceptive without actually reducing fracture risk. As we reported, in those subjects with at least 6 months of pre-DMPA medical history (176 pre-treatment fractures among 41876 future DMPA users and 1574 fractures after starting DMPA) the incidence rate ratio (IRR) for fracture 'after' vs 'before' DMPA use was 1.08 [95\% confidence interval (CI) $0.92-1.26$ ]. We subsequently expanded that analysis to include up to 2 years of fracture history in the same subpopulation of 41876 women $(582$ pre-treatment fractures in 64737 patient-years; 1574 fractures after starting DMPA), which yielded IRR 'after' vs 'before' of 1.01 (95\% CI 0.92-1.11), supporting our conclusion that DMPA had no meaningful effect on fracture risk in women who chose to use it.

In contrast, considering only the post-treatment follow-up period, our study confirmed the findings of others ${ }^{3}{ }^{4}$ that women who are offered and choose to use DMPA do tend to have more fractures than women who are not offered, or decline to use, DMPA. We agree with Dr Curry that reporting bias might play a role, because DMPA patients return to clinic every 3 months rather than annually. Possibly more important, however, is our observation that the incidence of peripheral fractures, most likely resulting from trauma, showed the greatest differential between DMPA users and non-users during follow-up, suggesting that the women to whom physicians tend to recommend DMPA may well experience more trauma than non-users. Several studies ${ }^{5}{ }^{6}$ have noted demographic, economic and other sociological differences between self- selected DMPA users and non-users, supporting the possibility that there is a higher underlying risk for trauma in women who choose DMPA.

The effect of DMPA on bone mineral density (BMD) has been clearly demonstrated in numerous studies, but like the effect of pregnancy and lactation on $\mathrm{BMD}$, the BMD decline seen with DMPA use has been shown to be largely reversible and does not appear to cause any increase in fracture risk.

\section{Lee L Lanza, ScD}

Director of Epidemiology, RTI Health Solutions, Waltham, MA, USA; llanza@rti.org

\section{Lisa J McQuay, MBioinf}

Senior Research Epidemiologist, RTI Health Solutions, Research Triangle Park, NC, USA; ljmcquay@rti.org

\section{Kenneth J Rothman, DrPH}

Vice-President for Epidemiology Research, RTI Health Solutions, Research Triangle Park, NC, USA; krothman@rti.org

\section{Henry G Bone, MD}

Section Chief of the Endocrinology Department, St John Hospital and Medical Center; Michigan Bone \& Mineral Clinic, Detroit, MI, USA;

hgbone.md@att.net

\section{Andrew M Kaunitz, MD}

Professor and Associate Chair, Department of Obstetrics and Gynecology, University of Florida College of Medicine-Jacksonville, FL, USA; andrew.kaunitz@jax.ufl.edu

\section{Zeev Harel, MD}

Professor of Pediatrics, Division of Adolescent Medicine/Hasbro Children's Hospital and Department of Pediatrics/Warren Alpert Medical School, Brown University, Providence, RI, USA; ZHarel@Lifespan.org

Quazi Ataher, PhD

Director of Epidemiology, Pfizer Inc., Collegeville, PA, USA; quazi.ataher@pfizer.com

Douglas Ross, MD

Senior Director of Medical Affairs, Pfizer Inc., Collegeville, PA, USA; douglas.ross@pfizer.com

Philip L Arena, BSPharm

Director of Safety Surveillance, Pfizer Inc., New York, NY, USA; philip.I.arena@pfizer.com

Kevin D Wolter, ${ }^{*} \mathrm{MD}$

Senior Director of Clinical Development, Pfizer Inc., New York, NY, USA; kevin.d.wolter@pfizer.com

*Corresponding author
Competing interests Doctors Ataher, Arena, Ross and Wolter are employees of Pfizer, Inc.

Provenance and peer review Not commissioned; internally peer reviewed.

J Fam Plann Reprod Health Care 2013;39:306. doi:10.1136/fprhc-2013-100759

\section{REFERENCES}

1 Curry L. Use of depot medroxyprogesterone acetate contraception and incidence of bone fracture. J Fam Plann Reprod Health Care 2013;39:206.

2 Lanza LL, McQuay LF, Rothman KJ, et al. Use of depot medroxyprogesterone acetate contraception and incidence of bone fracture. Obstet Gynecol 2013;121:593-600.

3 Meier CR, Brauchli YB, Jick SS, et al. Use of DMPA and fracture risk. J Clin Endocrin Metab 2010;95:4909-4916.

4 Vestergaard P, Rejnmark L, Mosekilde L. The effects of DMPA and intrauterine device use on fracture risk in Danish women. Contraception 2008;78:459-464.

5 Johnson CC, Burkman RT, Gold MA, et al. Longitudinal study of depot medroxyprogesterone acetate (Depo-Provera) effects on bone health: study design, population characteristics and baseline bone mineral density. Contraception 2008;77:239-248.

6 Secura GM, Allsworth JE, Madden T, et al. The Contraceptive CHOICE Project: reducing barriers to long-acting reversible contraception. Am J Obstet Gynecol 2010;115:e1-e77. 